\title{
The effect of chromium coating in RP technology for airfoil manufacturing
}

\author{
S DANESHMAND $^{1, *}, \mathrm{C}$ AGHANAJAFI ${ }^{2}$ and \\ A AHMADI NADOOSHAN ${ }^{3}$ \\ ${ }^{1}$ Islamic Azad University, Department of Mechanical Engineering, Science and \\ Research Branch, Tehran, Iran 81597-16778 \\ ${ }^{2}$ K. N. T. University of Technology, Department of Mechanical Engineering, \\ Tehran, Iran \\ ${ }^{3}$ Islamic Azad Universities, Majlesi Branch, Isfahan, Iran \\ e-mail: saeed_daneshmand@yahoo.com
}

MS received 21 July 2008; revised 8 April 2010; accepted 12 July 2010

\begin{abstract}
Most wind tunnel models are fabricated of all metal components using computerized numerical control (CNC) milling machines. Fabrication of metal wind tunnel models is very expensive and time consuming. The models can require months to manufacture and are often made by small high technology companies that specialize in wind tunnel model manufacture. Using rapid prototype manufacturing techniques and materials in this way significantly reduces time and cost of production of wind tunnel models. This study was done by fused deposition modelling and their ability to make components for wind tunnel models in a timely and cost effective manner. This paper discusses the application of wind tunnel model configuration constructed using FDM and FDM with chromium coating for subsonic wind tunnel testing. A study was undertaken comparing a rapid prototyping model constructed of FDM technologies using polycarbonate to that of a standard machined steel model. Results from this study show relatively good agreement among the three models and rapid prototyping method with chromium coating does have an effect on the aerodynamic characteristics which produced satisfactory results.
\end{abstract}

Keywords. Manufacturing; FDM; airfoil; rapid prototyping; wind tunnel; coating.

\section{Introduction}

Wind tunnel testing is an integral part of the design process in many industries. Whether an object is stationary or mobile, wind tunnels provide insight into the effects of air as it moves over or around the test model. Since the physics of flight depends on the proper flow of air to

${ }^{*}$ For correspondence 
produce lift and reduce drag, wind tunnel evaluations are essential in the aerospace industry. Even in an age of advanced computer simulation, aerospace engineers still rely on the testing of physical models to verify the computer data and establish baseline aerodynamic information. In the never-ending quest for more efficient airfoil, aerodynamics plays a very important part in vehicle design. Routinely, the aerospace companies employ wind tunnels to analyse their latest models. While these companies may test an entire vehicle, they will also evaluate the aerodynamics of individual components, such as tail, body and wing. To make the models for the wind tunnel, aerospace companies have relied on traditional manufacturing operations. They have used milling, turning and fabrication to convert metal and plastic into test models. These operations require programming, set-up and operator supervision, which add to lead time and cost. Considering the amount of material that ends up as chips on the floor, the material costs can be high. Rapid Prototype (RP) materials and methods have been considered as a potential source of improvements to conventional wind tunnel models. RP parts can generally be made much more rapidly and less expensively than conventional machined parts (Bohn Jan 1997). RP manufacturing is a field of high technology concerning the generation of three-dimensional solids using particles or layers of mostly polymeric materials. Rapid prototyping has become a widely used tool for the fabrication and evaluation of physical prototypes during the product development cycle. RP is becoming an increasingly important tool for manufacturing engineers in producing concept models, functional prototypes, and master patterns for tooling, airfoil, and casting (Cho et al 2000). As the technology continues to mature, it yields greater versatility and variety of equipment, resins, and materials, including thermoplastics and metals. Rapid prototyping methods currently in use include stereolithography (SLA), selective laser sintering (SLS), fused deposition modelling (FDM), and three-dimensional printing (3DP), all of which can help shorten the design cycle and bring products to market faster (De Leon et al 2000). Recently, RP has also been investigated regarding its ability to replace traditional mass manufacturing processes in applications where only one or a small number of individually shaped parts are required. Rapid prototyping uses advanced computer and laser technologies to produce complex three-dimensional prototypes in a fraction of the time required by more traditional technologies (Song et al 2002). The rapid prototyping process begins with a CAD solid model output to the appropriate RP file format. The file data is sliced into cross sections of 0.0762 to $0.254 \mathrm{~mm}$. thickness. The cross sections are then fabricated in a layer additive process using one of the three available RP technologies. The precursor study wind tunnel model was constructed using the fused deposition method (FDM) and FDM model with chromium coating. RP model constructed using FDM with polycarbonate as a material. ASTM A284 was chosen as the material for the machined metal model. Testing covered the Mach range of Mach 0.3 to Mach 0.75. Results from this study show that FDM and FDM model with chromium coating has rapidly gained acceptance as an alternative process for constructing wind tunnel test models. When compared to machining and model making, FDM is a faster, less expensive and more efficient method for making detailed and accurate test models. Distinguished by its durable and functional materials, FDM is well suited for this application.

\section{Fused deposition modelling (FDM)}

RP manufacturing is a field of high technology concerning the generation of three-dimensional solids using particles or layers of mostly polymeric materials (Thrimurthullu et al 2004). Two of the most popular RP techniques include stereolithography and fused deposition modelling (FDM). Both techniques build solid objects layer-by-layer based on data from a computer 


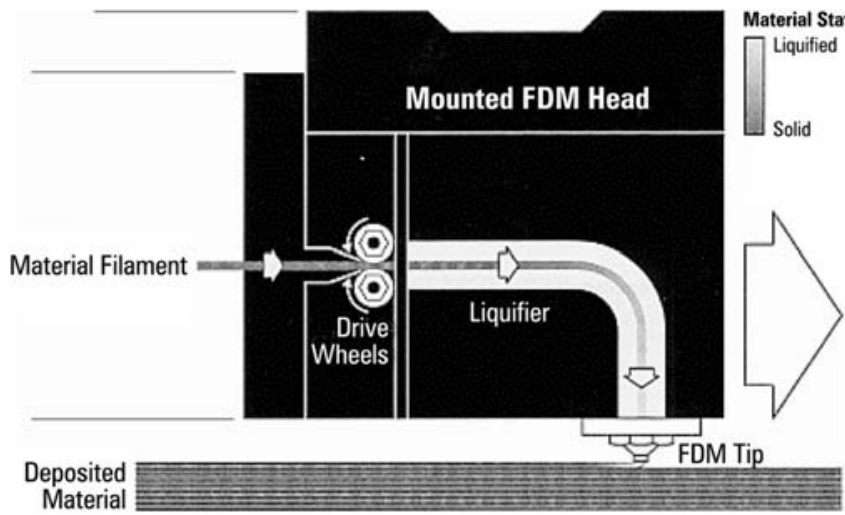

Figure 1. Fused deposition modelling (FDM) rapid prototyping process.

aided design (CAD). In FDM technique, filaments of heated thermoplastic are extruded from a tip that moves in the $\mathrm{x}-\mathrm{y}$ plane. Like a baker decorating a cake, the controlled extrusion head deposits very thin beads of material onto the build platform to form the first layer. The platform is maintained at a lower temperature, so that the thermoplastic quickly hardens (Steve Upcraft \& Richard Fletcher 2003). After the platform lowers, the extrusion head deposits a second layer upon the first. Supports are built along the way, fastened to the part either with a second, weaker material or with a perforated junction (figure 1).

\section{Model construction and surface quality}

FDM materials are of the strongest available in the additive fabrication market. The mechanical properties of ABS-M30, polycarbonate (PC), PC-ABS and polyphenolsulfone (PPSF) can withstand the forces and stresses induced as the air flow strikes the model's surface. The RP processes were fused deposition modelling (FDM) using material of Polycarbonate plastic. The fused deposition modelling involves the layering of molten beaded PC plastic material via a movable nozzle in $0.178 \mathrm{~mm}$ thick layers (Dimitrov et al 2007). Polycarbonate is an actual industrial-grade thermoplastic that is impact-resistant and structurally strong. Polycarbonate parts produced with FDM are dimensionally stable and will not shrink, warp, or absorb moisture. This high-performance engineering material can handle greater forces and loads than ABS material and is ideal for functional prototypes and end-use parts. Steel (ASTM A284) was chosen as the material for the machined metal model (Aghanajafi et al 2009). The material properties of ASTM A284 (St37) and PC are shown in tables 1 and 2. Three models were fabricated. The first model was from polycarbonate material and $0.178 \mathrm{~mm}$ Layer thickness. Second model was from steel and surface roughness $0.63 \mu \mathrm{m}(\mathrm{Ra})$. Third model

Table 1. Material properties of ASTM A284.

\begin{tabular}{llc}
\hline Mechanical properties & Units & ASTM A284 (St 37) \\
\hline Tensile strength, ultimate tensile & Mpa & 415 \\
Strength, yield & Mpa & 205 \\
Elongation at break & Per cent & 21 \\
\hline
\end{tabular}


Table 2. Material properties of polycarbonate (PC).

\begin{tabular}{lllr}
\hline Mechanical properties & Units & Test method & PC \\
\hline Tensile strength & Mpa & ASTM D638 & 52 \\
Tensile modulus & Mpa & ASTM D638 & 1,744 \\
Tensile elongation & Percent & ASTM D638 & 5 \\
Flexural strength & Mpa & ASTM D790 & 82 \\
Flexural modulus & Mpa & ASTM D790 & 2,193 \\
\hline
\end{tabular}

was from the FDM with chromium coating. FDM models can be produced within an accuracy of $\pm 0.127 \mathrm{~mm}$ up to $127 \mathrm{~mm}$. Accuracy on models greater than $127 \mathrm{~mm}$ is $\pm 0.0015 \mathrm{~mm}$ per millimeter. Figure 2 shows the tested model.

\section{Aerodynamic characteristics}

The aerodynamic loads are presented in a non-dimensional form. In the case of the force coefficients where $\mathrm{F}$ is either lift, drag, or slid force the corresponding coefficient will have the form (Katz \& Allen 1991):

$$
C_{F}=\frac{F}{\frac{1}{2} \rho Q_{\infty}^{2} S_{\text {ref }}},
$$

where $S_{\text {ref }}$ is a reference area (wing plan form area for wings), $\rho$ is the density of the free stream and $Q_{\infty}$ is the speed of the free stream (Katz \& Allen 1991). Thus:

$$
C_{A}=\frac{\text { Axial force }}{\frac{1}{2} \rho Q_{\infty}^{2} S_{\text {ref }}}, \quad C_{N}=\frac{\text { Normal force }}{\frac{1}{2} \rho Q_{\infty}^{2} S_{\text {ref }}} \quad \text { and } \quad C_{Y}=\frac{\text { Side force }}{\frac{1}{2} \rho Q_{\infty}^{2} S_{\text {ref }}} .
$$

Here, $C_{A}, C_{N}$ and $C_{Y}$ are axial force coefficient, normal force coefficient and side force coefficient, respectively. Similarly, the non-dimensional moment coefficient becomes (Katz \& Allen 1991):

$$
C_{M}=\frac{M}{\frac{1}{2} \rho Q_{\infty}^{2} S_{\mathrm{ref}} b}
$$

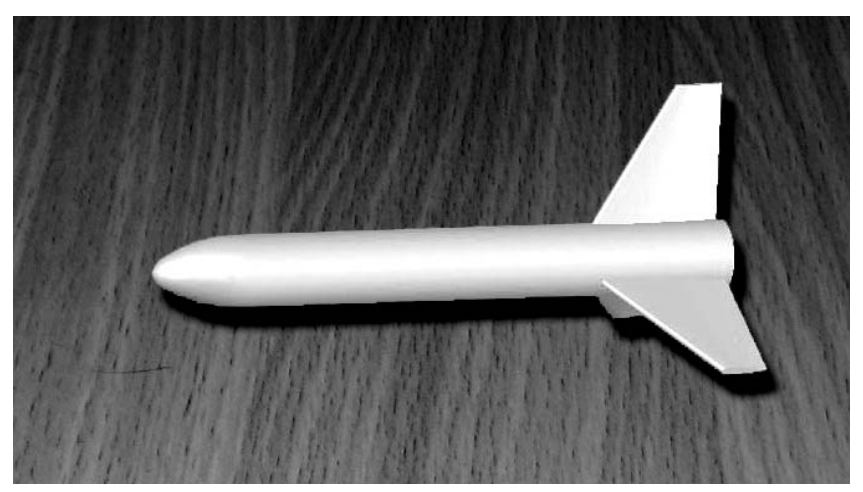

Figure 2. Model tested fused deposition modelling (FDM). 


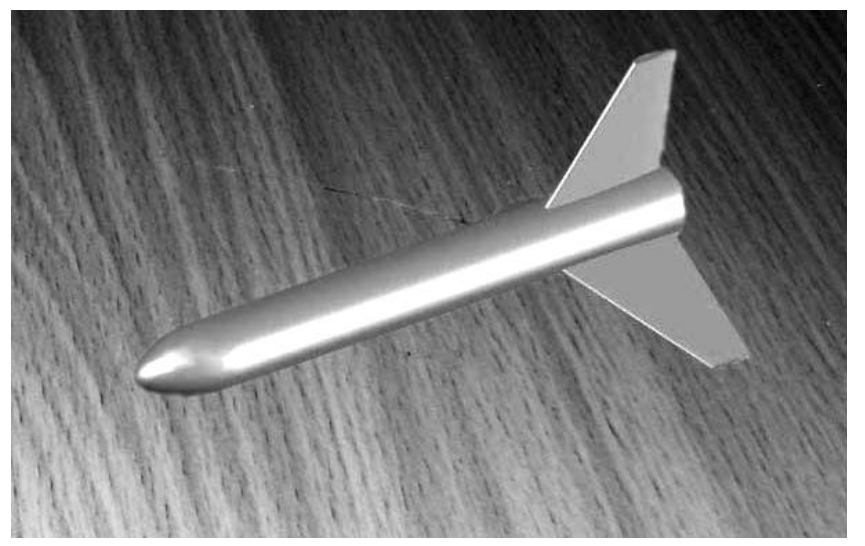

Figure 3. Wing-body-tail configuration.

Here, again $M$ can be a moment about any arbitrary axis and $b$ is a reference moment arm (e.g. wing span). Thus:

$C_{M}=\frac{\text { Pitching Moment }}{\frac{1}{2} \rho Q_{\infty}^{2} S_{\mathrm{ref}} c}, \quad C_{Y N}=\frac{\text { Yawing Moment }}{\frac{1}{2} \rho Q_{\infty}^{2} S_{\mathrm{ref}} b} \quad$ and $\quad C_{1 \beta}=\frac{\text { Rolling Moment }}{\frac{1}{2} \rho Q_{\infty}^{2} S_{\mathrm{ref}} b}$.

Here, $C_{M}, C_{Y N}$ and $C_{1 \beta}$ are pitching moment coefficient, yawing moment coefficient and rolling moment coefficient, respectively (Katz \& Allen 1991).

\section{Model configuration}

A wing-body-tail configuration was chosen for this test. First, this configuration would indicate possible deflections in the wings or tail due to loads and whether the manufacturing accuracy of the airfoil sections would adversely affect the aerodynamic data that resulted during testing (Springer 1998). Secondly, will the model be able to withstand the starting, stopping and operating loads in a blow down wind tunnel (Jones \& Pandey 1999). A preliminary computer aided design (CAD) file was available for RP model design and fabrication. This Geometry provided a basis for comparisons between RP models and machined metal models. The model configuration is shown in figure 3. The reference dimensions for this configuration are shown in table 3. A wind tunnel test over a range of Mach numbers from $0 \cdot 3$ to 0.75 was undertaken to determine the aerodynamic characteristics of the models at 3 selected numbers for the precursor study. These Mach numbers were 0.30, 0.50 and 0.75. Models were tested at angle-of-attack ranges from 2 degrees to 12 degrees at zero sideslip. The reference aerodynamic axis system and reference parameters for the precursor study are shown in figure 4 (Springer 1997a).

Table 3. Reference dimensions.

\begin{tabular}{llc}
\hline Reference dimension & \multicolumn{1}{c}{ Units } & Dimensions \\
\hline Length $\left(L_{\text {ref }}\right)$ & $\mathrm{mm}$ & 200 \\
Area $\left(S_{\text {ref }}\right)$ & $\mathrm{cm}^{2}$ & 48 \\
Moment point $\left(X_{\mathrm{MRP}}\right)$ & $\mathrm{mm}$ aft of nose & 140 \\
\hline
\end{tabular}




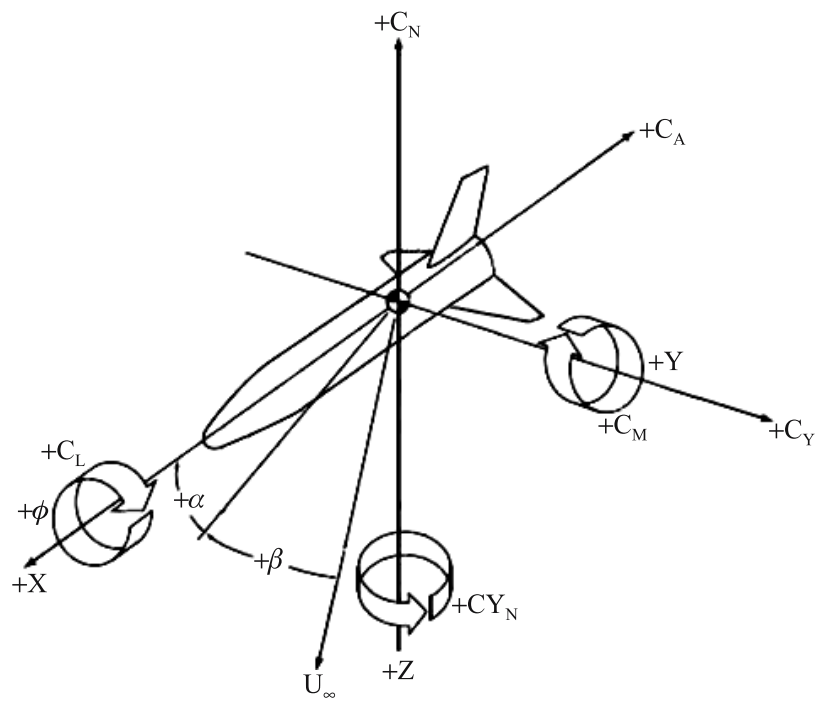

Figure 4. Aerodynamic axis system.

\section{Wind tunnel operating characteristics}

Engineers for verifying their calculations when a model is prepared, carry out the aerodynamic tests that start from wind tunnel and end to ambient conditions. Forces and moments measurement is the most purpose of test in the wind tunnels (Daneshmand et al 2008). The wind tunnel is an intermittent blow down tunnel, which operates by high-pressure air flowing from storage to atmosphere conditions. This will be used for characterizing power plant at different wind tunnel speed. This wind tunnel will also be used for the measurement of aerodynamic characteristics of the aircraft. Wind tunnel of size $0.6 \mathrm{~m} \times 0.6 \mathrm{~m} \times 1 \mathrm{~m}$ is shown in figure 5. For a small load measurement torque sensor is used and the arm of the torque sensor works as a mechanical amplifier. The tunnel flow is established and controlled with a servo-actuated gate valve. The air then passes through the test section which contains the nozzle blocks and test region. Downstream of the test section is a hydraulically controlled pitch sector that provides the capability of testing angles-of-attack ranging from -5 to +25

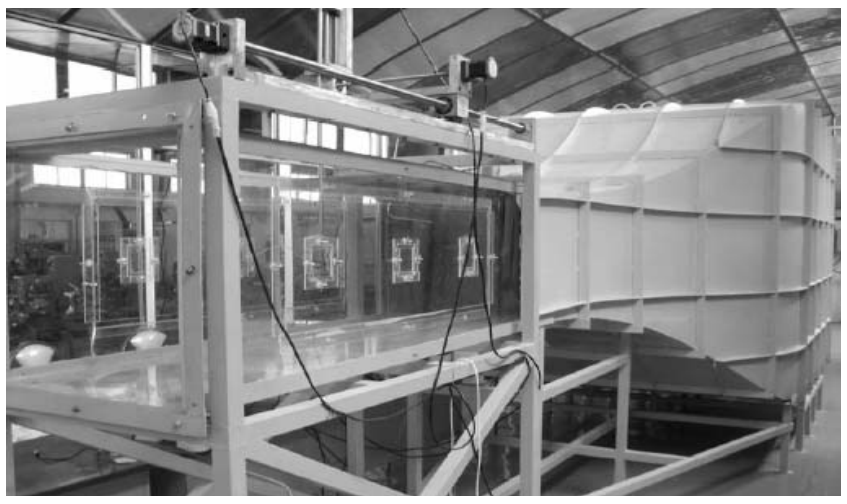

Figure 5. Wind tunnel. 
Table 4. Wind tunnel operating conditions.

\begin{tabular}{lrr}
\hline $\begin{array}{l}\text { Mach } \\
\text { number }\end{array}$ & $\begin{array}{c}\text { Dynamic } \\
\text { pressure }\end{array}$ & $\begin{array}{c}\text { Reynolds } \\
\text { number }\end{array}$ \\
\hline 0.3 & $8.96 \mathrm{kPa}$ & $9.18 \times 10^{4}$ \\
0.5 & $25.53 \mathrm{kPa}$ & $12.04 \times 10^{4}$ \\
0.75 & $30.42 \mathrm{kPa}$ & $15.52 \times 10^{4}$ \\
\hline
\end{tabular}

degrees during each run. The diffuser section has movable floor and ceiling panels, which are the primary means of controlling. Table 4 shows wind tunnel test section characteristics. A six-hole probe or a wake rake can be used to determine the wake characteristics of a test subject. Pilot probes are used to measure velocity gradients and to calculate drag through integration. Pressure ports can be used on a test subject to determine the forces on specific parts of a model or how forces are distributed across a model. Also, a boundary layer mouse can be employed to determine the boundary layer characteristics. Long force and moment data refers to the three forces (lift, drag, and side force) and three moments (roll, pitch, and yaw moment) that the wind applies to the test subject.

\section{Comparing the steel model and FDM model}

Coefficients of normal force, axial force, pitching moment, and lift over drag are shown at each of these Mach numbers. Testing was done over the mach range of 0.3 and 0.75 at 3 selected numbers for the precursor study. These Mach numbers were $0 \cdot 30,0.50$ and 0.75 . The longitudinal aerodynamic data show some small discrepancies between the two model types. The study showed that between Mach numbers of 0.3 to 0.75 , the longitudinal aerodynamic data showed good agreement between the metal model and FDM model up to about 10 degrees angle-of-attack when it started to diverge due to assumed FDM model surface bending under higher loading (figures 6 through 14). The greatest difference in the aerodynamic data

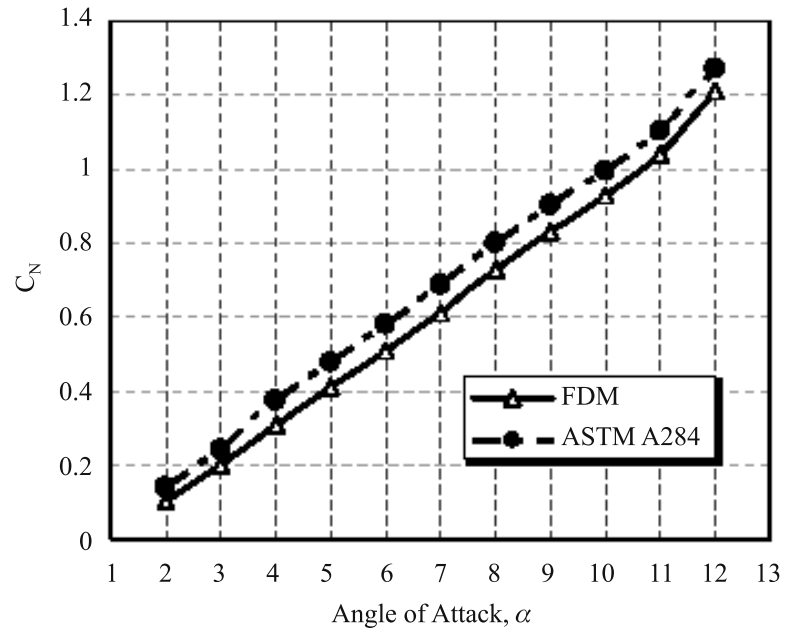

Figure 6. Comparison of normal force coefficient at mach $0 \cdot 3$. 

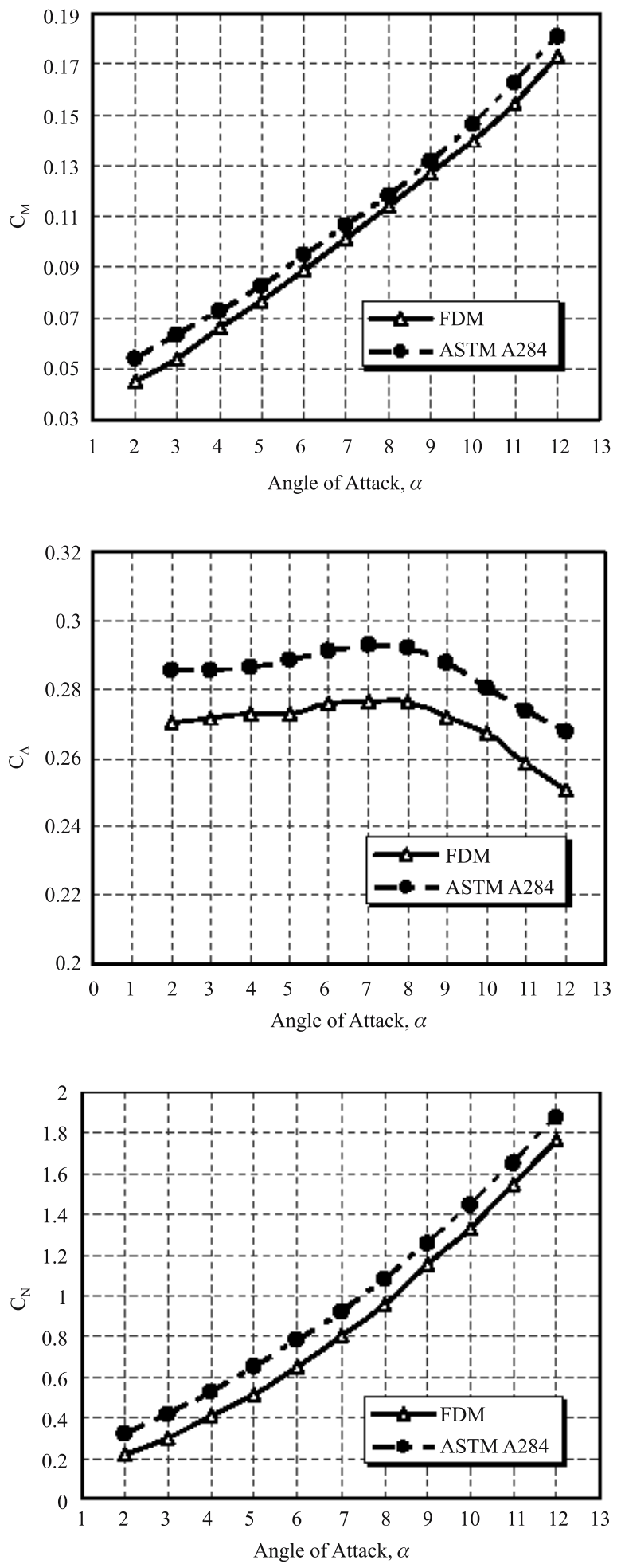

Figure 7. Comparison of pitching moment coefficient at mach $0 \cdot 3$.

Figure 8. Comparison of total axial force coefficient at mach $0 \cdot 3$.

Figure 9. Comparison of normal force coefficient at mach 0.5 . 

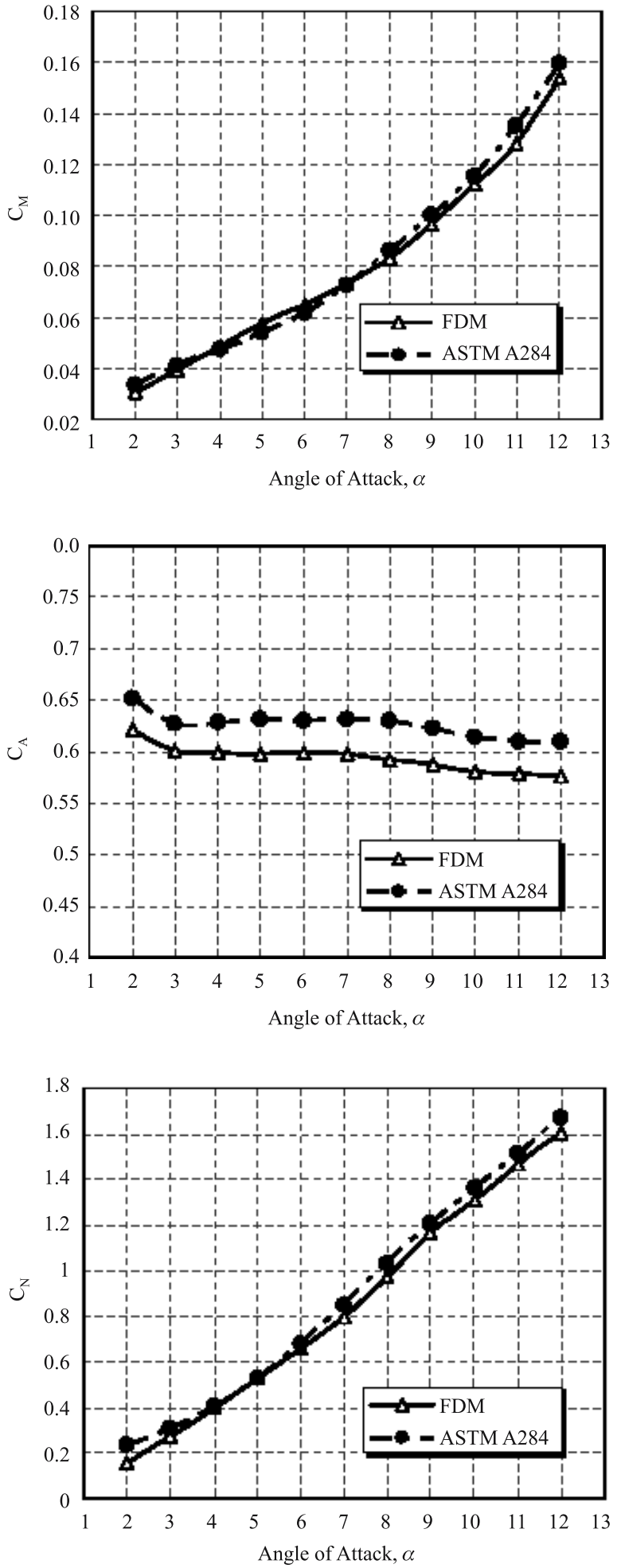

Figure 10. Comparison of pitching moment coefficient at mach $0 \cdot 5$.

Figure 11. Comparison of total axial force coefficient at mach 0.5 .

Figure 12. Comparison of normal force coefficient at mach 0.75 . 


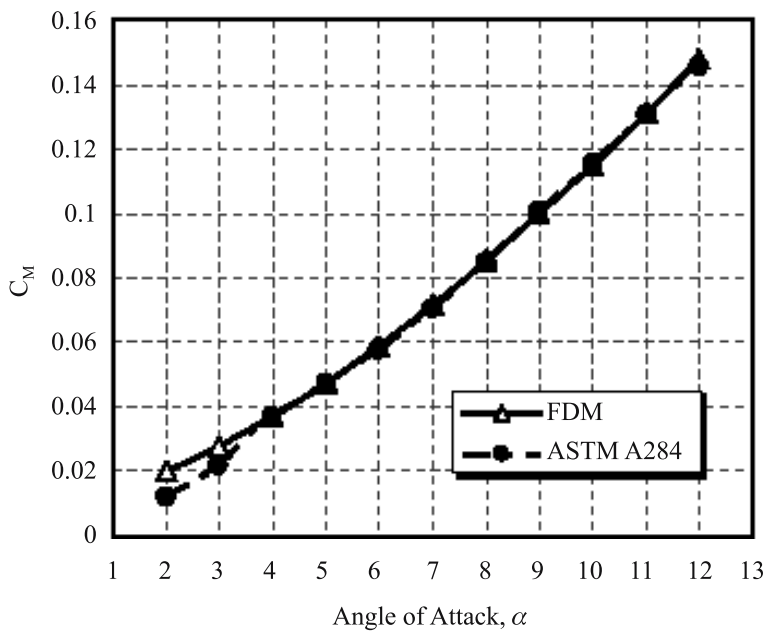

Figure 13. Comparison of pitching moment coefficient at mach 0.75 .

between the models at Mach numbers of 0.3 and 0.75 was in total axial force. All the models showed good agreement in pitching moment (figures 7, 10 and 13). In general, it can be said that RP model longitudinal aerodynamic data showed a slight divergence at higher angles-of attack when compared to the metal model data. The longitudinal aerodynamic data or data in the pitch plane showed approximately a 3 degree shift in the data between the RP and metal model for the normal force (figures 6, 9 and 12), and approximately a 1-degree data shift for the pitching moment (figures 7, 10 and 13). The total axial force was slightly lower for the RP model than the metal model (figures 8, 11 and 14).

\section{Comparing the steel model and FDM model with chromium coating}

Electroplating deposits a thin layer of metal on the surface of a part built using the FDM process. The coating gives the appearance of production metal or plated parts and provides a hard,

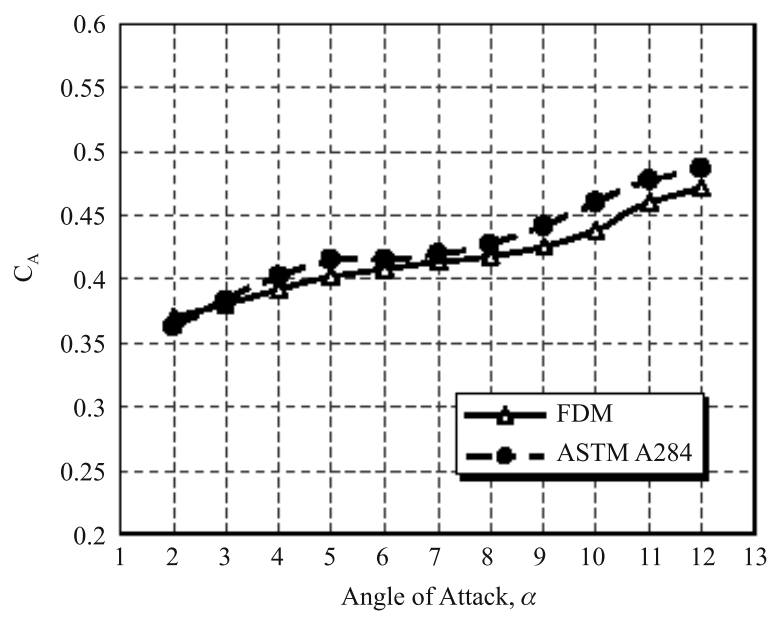

Figure 14. Comparison of total axial force at mach 0.75 . 


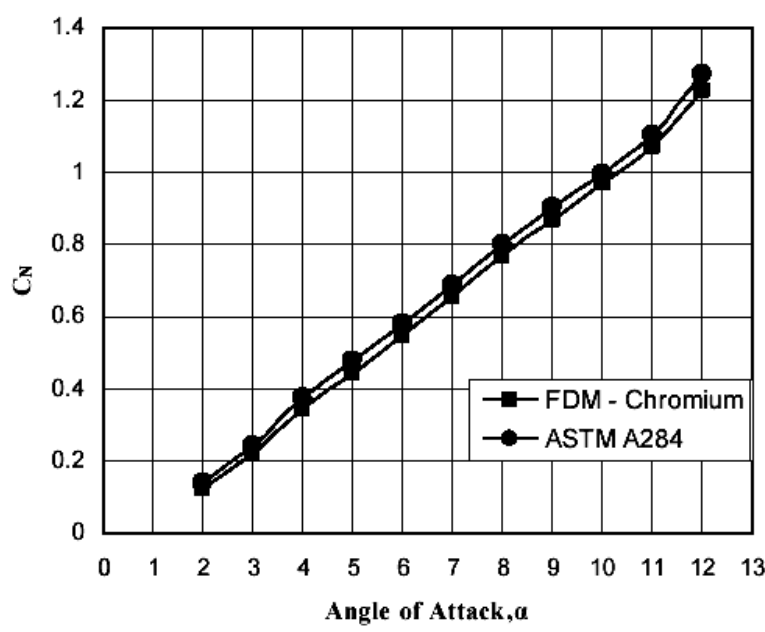

Figure 15. Comparison of normal force coefficient at mach $0 \cdot 3$.

wear-resistant surface with reflective properties. The electroplated part also has improved mechanical properties. With simple finishing techniques, FDM parts are ready for electroplating with alloys such as chromium, nickel, copper, silver and gold. Combining the properties of materials with those of a metal coating, the part has strength, durability and heat resistance that is ideal for functional applications. The FDM model did not have surface roughness as did the metal model, so runs were made to determine if the difference in this surface roughness would affect the aerodynamic coefficients. A surface roughness was simulated on the RP model by covering the full model in a layer of chromium. The model is chemically etched, which removes the butadiene molecules from the surface and improves bonding of the subsequent layers. Once etched, the part is then coated with a layer of palladium, which acts as an intermediate bonding agent, followed by a layer of chromium to provide the necessary durability. At this point, the model is placed in a tank containing a solution of the metal to be deposited and given a negative electric charge, which attracts the positively charged metal

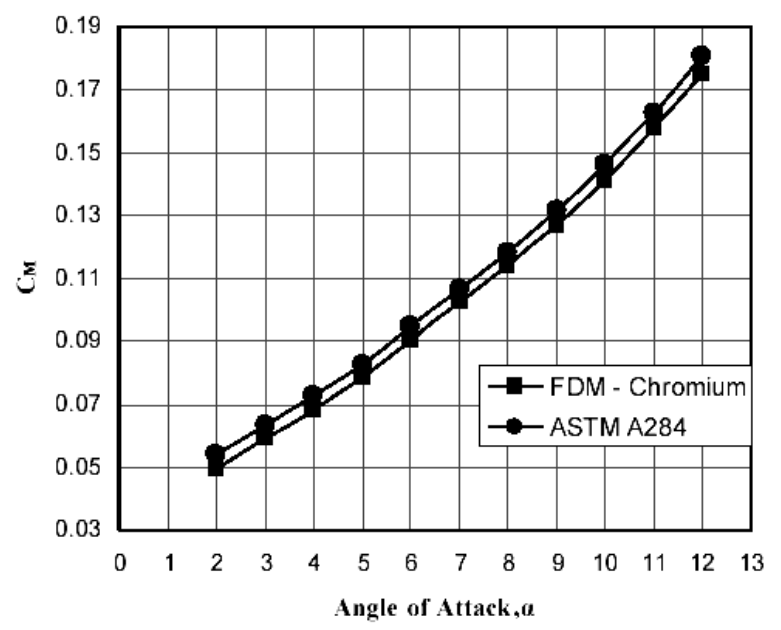

Figure 16. Comparison of pitching moment coefficient at mach $0 \cdot 3$. 

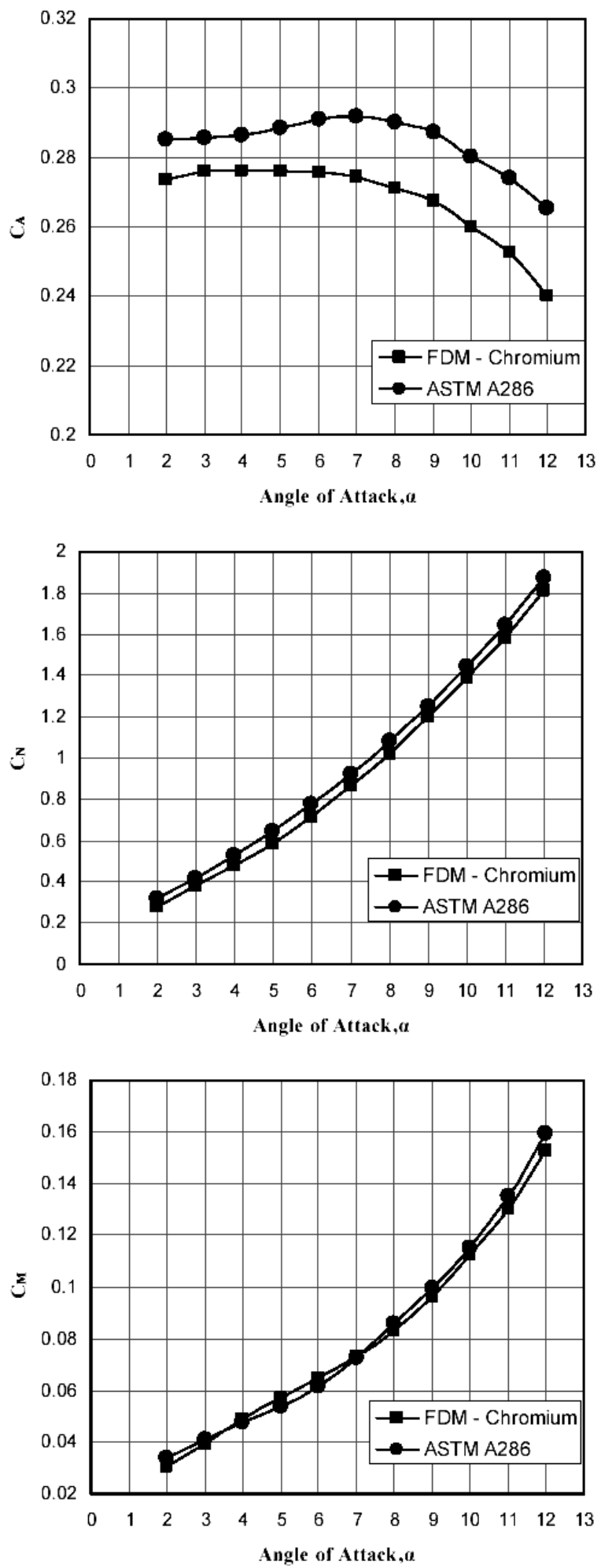

Figure 17. Comparison of total axial force coefficient at mach $0 \cdot 3$.

Figure 18. Comparison of normal force coefficient at mach $0 \cdot 5$.
Figure 19. Comparison of pitching moment coefficient at mach 0.5 . 

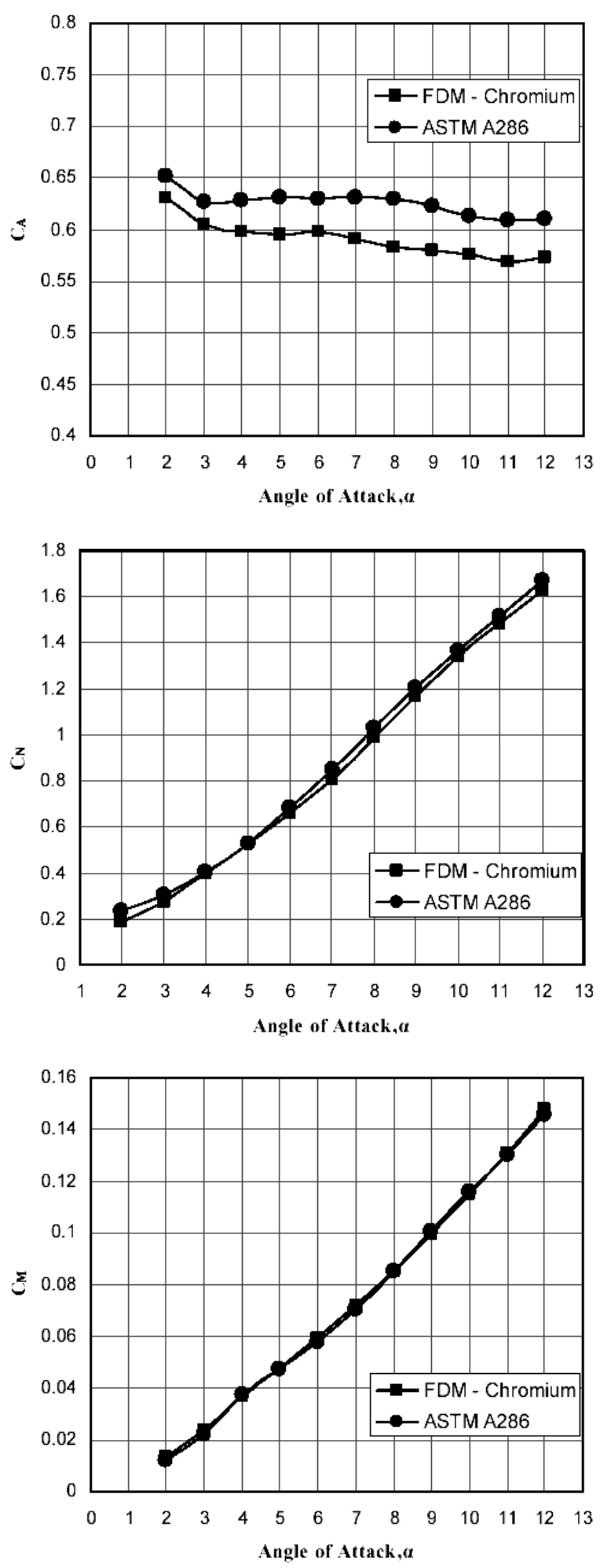

Figure 20. Comparison of total axial force coefficient at mach 0.5 .

Figure 21. Comparison of normal force coefficient at mach $0 \cdot 75$.
Figure 22. Comparison of pitching moment coefficient at mach 0.75 . 


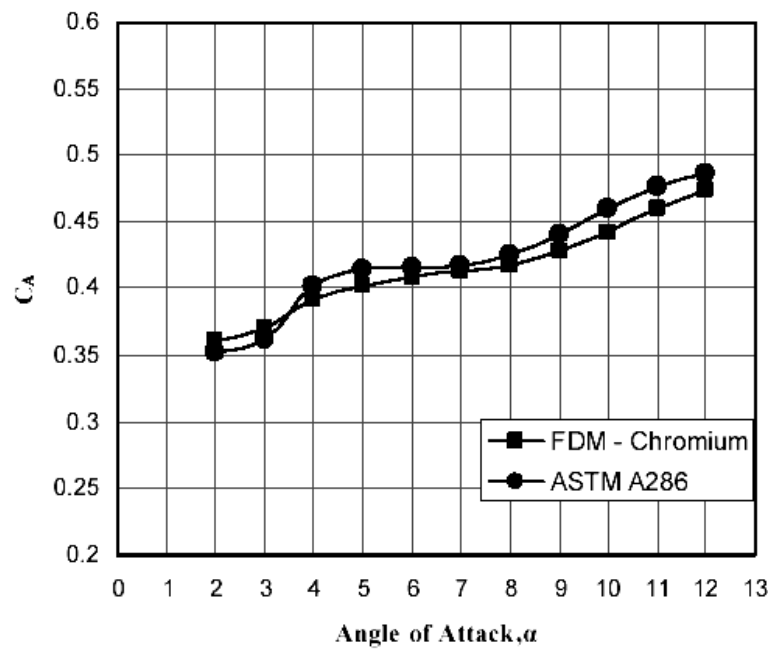

Figure 23. Comparison of total axial force at mach $0 \cdot 75$.

ions from the solution and becomes a solid metal again. The effect of electroplating on the model was also determined. The effect of these changes is shown in figures 15 through 23 . The application of electroplating had little effect on the aerodynamic characteristics except for axial force and its derivative coefficients. In these graphs it can be seen that surface roughness does have an effect on the aerodynamic characteristics. When testing at very high wind speeds, it is true that surfaces must be very smooth. However, at lower speeds, companies are using FDM models directly from the system.

\section{Data accuracy}

The data accuracy resulting from the test can be divided into source of error in model dimensions and surface roughness. The dimensions of each model must be compared. The contours of the models used in this test were measured at two wing sections, vehicle stations, tail sections, and the XY and XZ planes (Springer \& Cooper 1997b). A comparison of model dimensions is shown in table 5. Two sectional cuts were made on each wing, left and right;

Table 5. Model dimensions compared with theoretical (mm).

\begin{tabular}{lccc}
\hline & Steel & FDM & FDM-Coating \\
\hline Wing L1 & $0 \cdot 240$ & $0 \cdot 251$ & $0 \cdot 276$ \\
Wing L2 & $0 \cdot 110$ & $0 \cdot 246$ & $0 \cdot 267$ \\
Wing R1 & $0 \cdot 106$ & $0 \cdot 140$ & $0 \cdot 165$ \\
Wing R2 & $0 \cdot 137$ & $0 \cdot 220$ & $0 \cdot 242$ \\
Body 1 & $0 \cdot 170$ & $0 \cdot 130$ & $0 \cdot 155$ \\
Body 2 & $0 \cdot 048$ & $0 \cdot 110$ & $0 \cdot 134$ \\
Tail 1 & $0 \cdot 080$ & $0 \cdot 200$ & $0 \cdot 233$ \\
Tail 2 & $0 \cdot 070$ & $0 \cdot 150$ & $0 \cdot 175$ \\
XY plane & $0 \cdot 030$ & $0 \cdot 160$ & $0 \cdot 180$ \\
XZ plane & $0 \cdot 060$ & $0 \cdot 240$ & $0 \cdot 261$ \\
\hline
\end{tabular}


two on the body; two on the vertical tail, and one cut in the XY and XZ planes. This shows a representation of the maximum discrepancy in model dimensions relative to the baseline CAD model used to construct all the models at each given station. Surface finish consideration is that slight roughness can be beneficial for some applications (Daneshmand et al 2007). The orientation of the model in the FDM build chamber will affect feature detail and surface smoothness. For wind tunnel applications, it is best to orient the part for optimum surface quality. An ideal part orientation positions the critical contours in the X-Y plane to prevent stepping between layers. With this orientation, the contours are drawn as smooth, continuous curves as the FDM extrusion head deposits material. To improve the surface quality, the airfoil is stood on end, which yields smooth contours and layers that are in the same plane as the air flow. Building the airfoil in the vertical orientation will increase build time, but this is offset by the improvement in test data and the minimization, or elimination, of manual part finishing.

\section{Conclusions}

It can be concluded from this study that wind tunnel models constructed using FDM rapid prototyping and FDM model with chromium coating can be used in wind tunnel testing for aerodynamic database development. The initial FDM model did not produce good results due to problems with surface roughness in fabrication. This was corrected in the second model with chromium coating. FDM model with chromium coating was shown to be the best process with satisfactory results for a majority of the test conditions. When testing at very high wind speeds, it is true that surfaces must be very smooth. However, at lower speeds, are using FDM models directly from the system. For those instances where parts must be finished before going into the wind tunnel, there are options. Another surface finish consideration is that slight roughness can be beneficial for some applications. The differences between the configurations data can be attributed to multiple factors such as surface finish, and tolerances on the fabrication of the models. FDM will also preserve small, inaccessible features that are difficult, or impossible, to make with traditional methods. Using soluble supports, which simply dissolve away, engineers, can incorporate every detail in the wind tunnel model. Internal passages, baffles and pressure tap locations can be built directly in the object. This level of detail, and the dimensional accuracy of the FDM process, ensures the highest quality of data from wind tunnel testing. Cost savings and model design/fabrication time reductions of over a factor of two have been realized for RP techniques as compared to current standard model design/fabrication practices.

\section{References}

Aghanajafi C, Daneshmand S, Ahmadi Nadooshan A 2009 Investigation of surface roughness on aerodynamics properties. J. Aircraft 46(3): 981-987

Bohn Jan H 1997 Integrating rapid prototyping into the engineering curriculum—A case study. Rapid Prototyping J. 3(1): 32-37

Cho I, Lee K, Choi W, Song Y 2000 Development of a new type rapid prototyping system international. J. Machine Tools \& Manufacture 40(4): 1813-1829

Daneshmand S, Adelnia R, Aghanajafi C 2008 The effect of layer thickness on aerodynamic characteristics of wind tunnel RP models. J. Fluid Sci. Technol. 3(1): 22-30

Daneshmand S, Dehghani A R, Aghanajafi C 2007 Investigation of surface roughness on aerodynamics properties. J. Aircraft 44(5): 1630-1634 
De Leon, John E, Gary W 2000 Incorporating rapid prototyping into the engineering design curriculum. Eng. Design Graphics J. 64(1): 18-23

Dimitrov D, Schreve K, Taylor A, Vincent B 2007 Rapid prototyping driven design and realization of large components. Rapid Prototyping J. 13(2): 85-91

Jones Pandey R T 1999 The oblique wing craft design for transonic and low supersonic speeds. Acta Astronautic 4 Pergammon Press

Katz J Allen P 1991 Low speed aerodynamics from wing theory to panel method. McGraw-Hill book Co, ISBN 0-07-100876-4

Song Y, Yan Y, Zhang R, Xu R, Wang F 2002 Rapid prototyping and rapid tooling technology. J. Materials Process. Technol. 120(3): 237-42

Springer A, Cooper K, Roberts F 1997a Application of rapid prototyping models to transonic wind tunnel testing. AIAA 97-0988 35th Aerospace Sciences Meeting

Springer A, Cooper K, 1997b Comparing the aerodynamic characteristics of wind tunnel models produced by rapid prototyping and conventional methods. AIAA 97-2222 15th AIAA Applied Aerodynamics Conference

Springer A 1998 Evaluating aerodynamic characteristics of wind-tunnel models produced by rapid prototyping methods. J. Spacecraft and Rockets 35(6): 755-759

Steve Upcraft, Richard Fletcher 2003 The rapid prototyping technologies. J. Assembly Automation 23(4): 318-3308

Thrimurthullu K, Pandey P M, Reddy N V 2004 Part deposition orientation in fused deposition modelling. Inter. J. Machine Tools and Manufacture 44: 585-594 